\title{
Biological role of aldo-keto reductases in retinoic acid biosynthesis and signaling
}

\section{F. Xavier Ruiz ${ }^{\dagger}$, Sergio Porté, Xavier Parés and Jaume Farrés*}

Department of Biochemistry and Molecular Biology, Universitat Autònoma de Barcelona, Barcelona, Spain

\section{Edited by:}

Yi Jin, University of Pennsy/vania, USA

Reviewed by:

Ana Cristina Carvalho Rego, University of Coimbra, Portugal

Natalia Kedishvili, University of

Alabama at Birmingham, USA

\section{${ }^{*}$ Correspondence:}

Jaume Farrés, Department of

Biochemistry and Molecular Biology, Universitat Autònoma de Barcelona, E-08193 Bellaterra, Barcelona, Spain. e-mail: jaume.farres@uab.cat

\section{${ }^{\dagger}$ Present address:}

F. Xavier Ruiz, Structural Biology and Genomics Department, IGBMC, CNRS, INSERM, University of Strasbourg, 67404 IIIkirch, France.
Several aldo-keto reductase (AKR) enzymes from subfamilies $1 B$ and $1 C$ show retinaldehyde reductase activity, having low $K_{m}$ and $k_{\text {cat }}$ values. Only AKR1B10 and 1B12, with all-trans-retinaldehyde, and AKR1C3, with 9-cis-retinaldehyde, display high catalytic efficiency. Major structural determinants for retinaldehyde isomer specificity are located in the external loops ( $A$ and $C$ for AKR1B10, and B for AKR1C3), as assessed by site-directed mutagenesis and molecular dynamics. Cellular models have shown that AKR1B and $1 \mathrm{C}$ enzymes are well suited to work in vivo as retinaldehyde reductases and to regulate retinoic acid (RA) biosynthesis at hormone pre-receptor level. An additional physiological role for the retinaldehyde reductase activity of these enzymes, consistent with their tissue localization, is their participation in $\beta$-carotene absorption. Retinaldehyde metabolism may be subjected to subcellular compartmentalization, based on enzyme localization. While retinaldehyde oxidation to RA takes place in the cytosol, reduction to retinol could take place in the cytosol by AKRs or in the membranes of endoplasmic reticulum by microsomal retinaldehyde reductases. Upregulation of some AKR1 enzymes in different cancer types may be linked to their induction by oxidative stress and to their participation in different signaling pathways related to cell proliferation. AKR1B10 and AKR1C3, through their retinaldehyde reductase activity, trigger a decrease in the RA biosynthesis flow, resulting in RA deprivation and consequently lower differentiation, with an increased cancer risk in target tissues. Rational design of selective AKR inhibitors could lead to development of novel drugs for cancer treatment as well as reduction of chemotherapeutic drug resistance.

Keywords: aldo-keto reductase, retinaldehyde, retinoic acid, retinol, cancer

\section{INTRODUCTION}

Members of the aldo-keto reductase (AKR) superfamily are $\operatorname{NADP}(\mathrm{H})$-dependent cytosolic enzymes which fold into a typical $(\alpha / \beta)_{8}$-barrel. AKRs catalyze the reduction of a wide variety of carbonyl compounds (Jez et al., 1997; Barski et al., 2008). With regard to the biological function of human AKRs, they may be involved in the detoxification of electrophilic compounds, such as 4hydroxy-trans-2-nonenal generated under oxidative stress conditions. AKRs are also able to reduce a variety of lipophilic substrates, such as ketosteroids, ketoprostaglandins, and retinoids, which are hormone precursors. Thus, another function may be related to pre-receptor hormone regulation of the amount of ligand available for some nuclear receptors and, therefore, to participation in transcriptional gene control. Lastly, they are considered as phase I drug-metabolizing enzymes and can either detoxify or activate

\footnotetext{
Abbreviations: ADH, alcohol dehydrogenase; AKR, aldo-keto reductase; ALDH, aldehyde dehydrogenase; $\mathrm{BCO}$, $\beta$-carotene $15,15^{\prime}$-monooxygenase 1 ; CRABP, cellular retinoic acid binding protein; CRBP-I, -II, cellular retinol binding protein type I, II; CYP26, cytochrome P450 family 26; LRAT, lecithin:retinol acyl transferase; MD, molecular dynamics; MDR, medium-chain dehydrogenase/reductase; PPAR $\gamma$, peroxisome proliferator-activated receptor $\gamma$; RA, retinoic acid; RALDH, retinaldehyde dehydrogenase; RAR, retinoic acid receptor; RBP, retinol binding protein; REH, retinyl ester hydrolase; ROS, reactive oxygen species; RXR, retinoid X receptor; SDR, short-chain dehydrogenase/reductase; STRA6, stimulated by retinoic acid gene 6; TTR, transthyretin.
}

xenobiotic compounds (i.e., polycyclic aromatic hydrocarbons; Penning and Drury, 2007).

With respect to the human AKRs, members of the AKR1B subfamily are of special interest. AKR1B1, the classical aldose reductase, is related to secondary diabetic complications, while AKR1B10 is induced in cancer cells. Although these two AKRs share $71 \%$ sequence identity, they show very different kinetic properties with some relevant substrates like retinaldehyde or glucose. Thus, AKR1B10 is a retinaldehyde reductase with a much higher $k_{\mathrm{cat}}$ value than that of AKR1B1, while glucose is reduced by AKR1B1 but not by AKR1B10. Recently, AKR1B10 has emerged as a tumor marker since it is overexpressed in different types of cancers, featuring hepatocellular carcinoma and lung cancer correlated with tobacco smoking (Ruiz et al., 2009; Wang et al., 2009; Díez-Dacal et al., 2011).

AKR1C1-AKR1C4, also known as human hydroxysteroid dehydrogenases, share $86 \%$ sequence identity, but the individual enzymes show different substrate specificity, inhibitor selectivity, and tissue expression pattern. AKR1C3 is one of the most interesting enzymes, with increasing evidence strongly supporting its involvement in cancer development (Jin and Penning, 2007; Penning and Byrns, 2009; Ruiz et al., 2011b).

The term "retinoid" refers to compounds derived from vitamin A (retinol), where their basic structure is divided into three domains: a cyclohexene ring or $\beta$-ionone, an aliphatic chain with 
four conjugated double bonds, and a polar group which may show different oxidation states. The different configuration of these double bonds leads to different stereoisomers, being the most frequent all-trans, 9-cis, 11-cis, and 13-cis (Blomhoff and Blomhoff, 2006). Retinol and its derivatives retinaldehyde and retinoic acid (RA) are essential for the growth and maintenance of many body tissues, such as skin, bone, and vasculature, as well as for the visual cycle (11-cis-retinaldehyde) and immune function. They also play a role in reproduction, embryonic growth, and development. In this sense, RA is a key molecule in the development of different vertebrate organs and tissues by promoting cell differentiation and apoptosis. RA has also a role in several pathological conditions, such as skin diseases, premature birth, and rheumatoid arthritis. Various human cancers have altered retinoid metabolism and low RA levels, which favor tumor progression (Theodosiou et al., 2010; Tang and Gudas, 2011).

Vitamin A incorporation in the body occurs through dietary intake of animal products, which are a source of retinyl esters, and from the consumption of fruits and vegetables, which are a source of carotenoids, mainly $\beta$-carotene (Figure 1A). In the first case, retinol is absorbed by the enterocyte cell after retinyl esters have been hydrolyzed in the small intestine. In the second case, $\beta$-carotene is absorbed directly by passive diffusion, and then in the enterocyte is split into two retinaldehyde molecules due
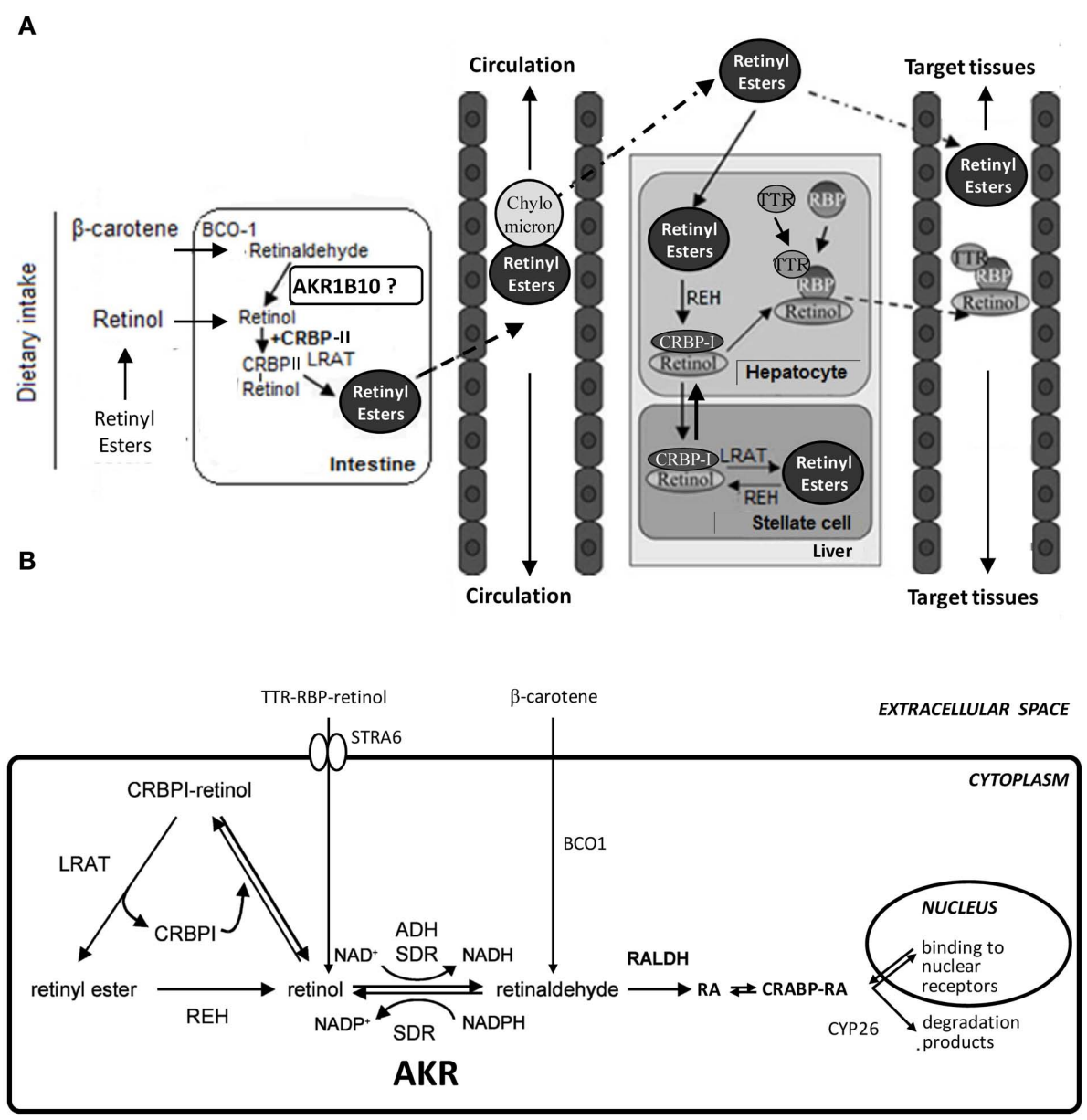

FIGURE 1 | Schematic diagram of retinoid absorption, transport, and metabolism. (A) Upon dietary intake and intestinal absorption, retinoids, and carotenoids are converted to retinol, which is bound to CRBP-II. Retinol is further processed to retinyl esters, incorporated into chylomicrons, and transported to the liver. In hepatocytes, retinyl esters are hydrolyzed to retinol which forms a complex with CRBP-I. Retinol can then be transferred to stellate cells for storage as retinyl esters. Alternatively, retinol may bind to RBP, and the retinol:RBP complex is bound to TTR and transferred to circulation for transport to target tissues. Binding to TTR reduces renal clearance. Adapted with permission from (Theodosiou et al., 2010). Copyright@2010, Birkhäuser Verlag, Basel. (B) In the target tissues, STRA6, a cell-surface receptor for RBP, facilitates retinol entry. Carotenoids may be also a major source of cellular retinoids. Levels of CRBP-I, LRAT, REH, and oxidoreductases (ADH, SDR, AKR, and RALDH) influence the retinoid flow either toward the storage pathway or the synthesis of RA, which is bound to CRABP. RA enters the nucleus, where it binds to nuclear receptors. RA is degraded and eliminated by CYP26 enzymes. Adapted with permission from (Parés et al., 2008). Copyright@2008, Birkhäuser Verlag, Basel. ADH, alcohol dehydrogenase; AKR, aldo-keto reductase; $B C 01, \beta$-carotene $15,15^{\prime}$-monooxygenase 1 ; CRABP, cellular retinoic acid binding protein; CRBP-I, -II, cellular retinol binding protein type I, -II; CYP26, cytochrome P450 family 26; LRAT, lecithin:retinol acetyltransferase; RA, retinoic acid; RALDH, retinaldehyde dehydrogenase; RBP, retinol binding protein; REH, retinyl ester hydrolase; SDR, short-chain dehydrogenase/reductase; STRA6, stimulated by retinoic acid gene 6; TTR, transthyretin. 
to the activity of $\beta$-carotene $15,15^{\prime}$-monooxygenase 1 (BCO1). The liver is another tissue which contributes significantly to $\beta$ carotene cleavage. Later, retinaldehyde is reduced to retinol. In the cell, retinol has two metabolic alternatives: storage or oxidative metabolism. One form of storage is through binding to cellular retinol binding protein type I and type II (CRBP-I and II, respectively). CRBP-I shows wide tissue expression, while CRBPII is expressed in the small intestine. In the enterocyte, retinol is attached to CRBP-II, and through the action of lecithin:retinol acyl transferase (LRAT) is esterified with fatty acids to yield long-chain esters of retinol. These are packaged into chylomicrons and are transported to the liver parenchymal cells where they are captured by specific receptors and transferred to stellate cells for storage, which constitutes $50-80 \%$ of body retinol in the form of retinyl esters. When required in the peripheral tissues, retinyl esters are hydrolyzed to retinol by retinol ester hydrolase (REH). The retinol generated is secreted and transported in the blood as a complex between retinol and the plasmatic retinol binding protein (RBP), which in turn is complexed with transthyretin (TTR) to reduce its glomerular filtration. Over $90 \%$ of retinol entering the cell is recycled to the plasma, and only a small part is esterified for storage, activated to RA or catabolized (Theodosiou et al., 2010; Harrison, 2012; Shirakami et al., 2012).

Biosynthesis of RA, the most potent biologically active metabolite of vitamin A, requires two oxidative steps (Figure 1B). Members of three oxidoreductase superfamilies have been implicated in the reversible oxidation of retinol to retinaldehyde, which is the pathway rate-limiting step (Napoli, 1999; Belyaeva et al., 2008). The participation of cytosolic alcohol dehydrogenases (ADH) from the medium-chain dehydrogenase/reductase (MDR) superfamily and of microsomal short-chain dehydrogenases/reductases (SDR) has been deeply studied. More recently, the AKR superfamily has been added as a novel group of cytosolic enzymes that could contribute to retinoid redox conversions. Based on the cofactor specificity, $\mathrm{ADH}$ (NAD-dependent) may work in the oxidative direction, AKRs (NADPH-dependent) in the reductive direction, while SDR show examples of both specificities.

The control of retinaldehyde levels is essential in the regulation of RA synthesis and, therefore, of its signaling role. Once retinaldehyde is synthesized, it has two alternative metabolic fates, its irreversible oxidation to RA by the action of aldehyde dehydrogenases (ALDH or RALDH) or its reduction back to retinol by retinaldehyde reductases. Synthesized RA binds to cellular RA binding protein (CRABP) and is transported to the cell nucleus where it binds to retinoid receptors. These can be divided into two subgroups: RA receptors (RAR), binding the isomers all-trans and 9-cis-RA, and retinoid X receptors (RXR), binding 9-cis-RA with high affinity, but not all-trans-RA. RAR/RXR heterodimers are bound to RA response elements (RARE) in DNA. Ligand binding induces a conformational change in the RAR/RXR heterodimers which promotes gene transcription. While RAR only forms heterodimers with RXR receptor (RAR-RXR), RXR is capable also to form heterodimers with thyroid hormone (RXR-TR), vitamin $D$ (RXR-DR), and peroxisomal proliferator-activated (RXR-PPAR) receptors. It appears that the RXR activity is subordinated to the presence of ligand bound to RAR in the heterodimer (Pogenberg et al., 2005). There is a balance between synthesis and catabolism to control RA levels. RA catabolism to more oxidized metabolites such as 4-hydroxy-RA or 4-oxo-RA occurs primarily through enzymes from the CYP26 family (Parés et al., 2008; Theodosiou et al., 2010; Tang and Gudas, 2011; Kumar et al., 2012).

The first AKR enzyme reported to display activity with retinoids was chicken AKR or AKR1B12 (Crosas et al., 2001). Since then, a significant amount of data has been reported on AKRs and retinoids. In this review, this relevant topic will be discussed, as AKRs are being established as enzymes that participate in the precise fine tuning required for the first and regulatory step of RA biosynthesis. Regulation of this pathway by AKRs and its relationship with retinoid body uptake and cell proliferation will also be approached because of its pathological relevance.

\section{CHARACTERIZATION OF AKRS AS RETINALDEHYDE REDUCTASES \\ ACTIVITY ASSAY METHODOLOGIES AND KINETIC RESULTS FOR AKR ENZYMES WITH RETINOIDS}

In vitro kinetic studies on AKR enzymes with retinoids are fundamental to investigate isomer specificity, inhibitor selectivity, and structure-function relationships. Retinoids are highly unstable hydrophobic compounds displaying very low solubility in water-based solvents and being susceptible to photodegradation, double-bond isomerization, and oxidation reactions. Thus, they need to be handled under dim red light, and properly solubilized and stabilized. In order to overcome these difficulties, two different methodologies have been used to perform kinetic studies with retinoids: (1) the $\mathrm{ADH}$ enzymatic assay (or Tween 80 assay), and (2) the SDR enzymatic assay (or HPLC assay), both reviewed in Parés et al. (2008).

\section{The ADH enzymatic assay (or Tween 80 assay)}

This assay is characterized by the use of an aqueous buffer containing a low amount of the non-ionic detergent Tween 80 (polyoxyethylene (20) sorbitan monooleate) and the spectrophotometric measurement of the reaction at $25^{\circ} \mathrm{C}$, following retinaldehyde absorbance at $400 \mathrm{~nm}$, where retinol does not absorb. Table 1 lists the $k_{\text {cat }}$ values of the AKR1 enzymes obtained by using this method. $K_{\mathrm{m}}$ values are not included because Tween 80 behaves as an apparently competitive inhibitor and thus, at the concentration used in the assay, there is a 10- to 100 -fold increase of the retinoid $K_{\mathrm{m}}$ values (Martras et al., 2004; Ruiz et al., 2009). Some of the values in Table 1 may not be fully comparable since kinetic studies were performed in different laboratories using different protein sources and methodologies, under various experimental conditions. Thus, AKR1B12 results were obtained by using tissuepurified instead of recombinant protein. Constants for AKR1B13, $1 \mathrm{~B} 14,1 \mathrm{~B} 17$, and $1 \mathrm{C} 15$ were measured with $0.01 \%(\mathrm{v} / \mathrm{v})$ Tween 80 instead of the widely used $0.02 \%$ concentration. Other laboratories used a high concentration of organic solvent (e.g., $8 \%$, v/v, dimethylsulfoxide). Another added trouble with this methodology is its low reproducibility due to the high absorbance of retinaldehyde at $400 \mathrm{~nm}$ combined with the low activity rate shown by AKR1 enzymes, resulting in high and variable background which must be subtracted during activity assays. While this methodology may still serve to perform routine determination of enzyme activity, it is not useful for comparison of kinetic parameters with 
Table 1 | Catalytic constants $\left(k_{\text {cat }}, \min ^{-1}\right)$ of AKR1 enzymes with retinaldehyde isomers, obtained spectrophotometrically in the presence of Tween 80 .

\begin{tabular}{|c|c|c|}
\hline Enzyme & All-trans-retinaldehyde & 9-cis-Retinaldehyde \\
\hline $1 \mathrm{~A} 2$ & N.A. ${ }^{a}$ & N.A. ${ }^{a}$ \\
\hline 1B1 & $0.37^{b}$ & 2.84 \\
\hline 1B10 & $17.8^{\mathrm{b}}$ & 5.20 \\
\hline 1B3 & $11.6^{d}$ & N.D. \\
\hline 1B7 & $9.73^{d}$ & N.D. \\
\hline 1B8 & $15.3^{d}$ & N.D. \\
\hline 1B9 & 0.11 & N.A. \\
\hline 1B12 & $17.0^{\mathrm{e}}$ & $8.62^{\mathrm{e}}$ \\
\hline $1 \mathrm{~B} 13$ & N.A. ${ }^{f}$ & N.D. \\
\hline 1B14 & N.A. ${ }^{g}$ & N.D. \\
\hline 1B17 & $0.58^{h}$ & N.D. \\
\hline $1 \mathrm{C} 7^{*}$ & L.A. ${ }^{i}$ & N.D. \\
\hline $1 \mathrm{C} 15$ & $1.2^{j}$ & $2.8^{j}$ \\
\hline
\end{tabular}

Activity was determined in $0.1 \mathrm{M}$ sodium phosphate, $\mathrm{pH} 7.5,0.02 \%$ Tween 80, $0.2 \mathrm{mM} \mathrm{NADPH}$, at $25^{\circ} \mathrm{C}$. ND, not determined; $N A$, no activity was

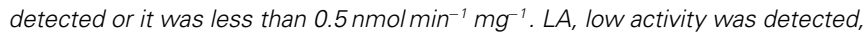
$4 \mathrm{nmol} \mathrm{min}{ }^{-1} \mathrm{mg}^{-1}$. ${ }^{*}$ Kinetics was performed in $0.1 \mathrm{M}$ potassium phosphate buffer, $\mathrm{pH} 6.5$, at $37^{\circ} \mathrm{C}$, and products were analyzed by reverse phase HPLC equilibrated with $80 \%\left(\mathrm{~V} / \mathrm{V}\right.$ ) acetonitrile in water. ${ }^{a}$ Crosas et al. (2003), ${ }^{b}$ Gallego et al. (2007b), ${ }^{\circ}$ Quinn et al. (2008), d Joshi et al. (2010), ${ }^{\circ}$ Crosas et al. (2001), ${ }^{f}$ Endo et al. (2009), ${ }^{g}$ Endo et al. (2010a), ${ }^{h}$ Endo et al. (2010b), 'Endo et al. (2001), 'Endo et al. (2007).

other enzymes, such as SDR, where activity has been typically determined by using detergent-free buffer (Gough et al., 1998; Parés et al., 2008).

\section{The SDR enzymatic assay (or HPLC assay)}

This assay uses an aqueous buffer containing retinoid/bovine serum albumin at $1: 1$ molar ratio, reaction at $37^{\circ} \mathrm{C}$, followed by retinoid extraction with hexane and analysis of the reaction products by HPLC. Determination of the reaction rate is based on the percentage of substrate conversion. Compared to the Tween 80 assay, the HPLC assay is far more reproducible, it does not alter the $K_{\mathrm{m}}$ values, requires a lower amount of substrate and is also suitable for cell culture experiments. Indeed, the comparative activity analysis side-by-side of ADH, SDR, and AKRs with retinoids revealed that all enzymes exhibited low and similar $K_{\mathrm{m}}$ values, $1 \mu \mathrm{M}$ or lower, while they differed in their $k_{\mathrm{cat}}$ values. Therefore, when possible, it is highly recommended to choose this method instead of the Tween 80 assay.

Tables 2 and 3 show kinetic constants of AKR1 enzymes using the HPLC assay. As it can be observed, $K_{\mathrm{m}}$ values keep close to $1 \mu \mathrm{M}$ or lower, which is in the physiological range of retinol concentration (Hollander and Muralidhara, 1977; Quick and Ong, 1990; Harrison, 2012). In contrast, $k_{\text {cat }}$ values are clearly distinct between different enzymes (Gallego et al., 2006; Ruiz et al., 2011b). None of the rodent enzymes characterized displayed high $k_{\mathrm{cat}}$ values, leaving human AKR1B10 and chicken AKR1B12 as the sole potent all-trans-retinaldehyde reductases of the superfamily (Gallego et al., 2006, 2007b; Ruiz et al., 2011a). On the other hand, human AKR1C enzymes have been shown to use preferentially
Table 2 | Kinetic constants of AKR1 enzymes with retinaldehyde isomers, obtained by the HPLC assay in the presence of BSA.

\begin{tabular}{|c|c|c|c|c|c|c|}
\hline \multirow[t]{2}{*}{ Enzyme } & \multicolumn{3}{|c|}{ All-trans-retinaldehyde } & \multicolumn{3}{|c|}{ 9-cis-Retinaldehyde } \\
\hline & $K_{\mathrm{m}}$ & $k_{\text {cat }}$ & $k_{\text {cat }} / K_{\mathrm{m}}$ & $K_{\mathrm{m}}$ & $k_{\text {cat }}$ & $k_{\text {cat }} / K_{\mathrm{m}}$ \\
\hline $1 \mathrm{~B} 1^{\mathrm{a}}$ & 1.1 & 0.35 & 320 & 0.4 & 0.7 & 1500 \\
\hline $1 \mathrm{~B} 3^{\mathrm{b}}$ & 1.0 & 0.52 & 540 & & N.D. & \\
\hline $1 \mathrm{~B} 7^{\mathrm{b}}$ & 0.5 & 0.02 & 42 & & N.D. & \\
\hline $1 \mathrm{~B} 8^{\mathrm{b}}$ & 2.1 & 0.05 & 22 & & N.D. & \\
\hline $1 \mathrm{Bg}$ & 2.0 & 0.27 & 140 & & N.D. & \\
\hline $1 \mathrm{~B} 10^{\mathrm{a}}$ & 0.6 & 27 & 45000 & 0.7 & 0.9 & 1300 \\
\hline 1B12 & 0.6 & 2.5 & 4100 & & N.D. & \\
\hline $1 \mathrm{C} 1^{\mathrm{C}}$ & & L.A. & & 0.48 & 0.18 & 370 \\
\hline $1 \mathrm{C} 2^{\mathrm{c}}$ & & N.A. & & & N.A. & \\
\hline $1 \mathrm{C} 3^{\mathrm{C}}$ & 1.4 & 0.60 & 430 & 0.40 & 13 & 32,500 \\
\hline $1 \mathrm{C} 4^{\mathrm{c}}$ & 0.31 & 0.24 & 790 & 0.80 & 0.40 & 500 \\
\hline
\end{tabular}

Activities were determined in $90 \mathrm{mM} \mathrm{KH_{2 }} \mathrm{PO}_{4}, 40 \mathrm{mM} \mathrm{KCl}, \mathrm{pH} 7.4,0.5 \mathrm{mM}$ $N A D P H, 37^{\circ} \mathrm{C}$. NA, no activity; $N D$, not determined; $L A$, low activity was detected, $0.56 \mathrm{nmol} \mathrm{min}^{-1} \mathrm{mg}^{-1}$. Units: $K_{m}(\mu M), k_{\text {cat }}\left(\mathrm{min}^{-1}\right), k_{\text {cat }} / K_{m}\left(\mathrm{mM}^{-1} \mathrm{~min}^{-1}\right)$. a Gallego et al. (2007b), b Ruiz et al. (2011a), c Ruiz et al. (2011b).

Table 3 | Kinetic constants of AKR1 enzymes with retinol isomers, obtained by the HPLC assay in the presence of BSA.

\begin{tabular}{|c|c|c|c|c|c|c|}
\hline \multirow{2}{*}{ Enzyme } & \multicolumn{3}{|c|}{ All-trans-retinol } & \multicolumn{3}{|c|}{ 9-cis-Retinol } \\
\hline & $K_{\mathrm{m}}$ & $\boldsymbol{k}_{\text {cat }}$ & $\boldsymbol{k}_{\text {cat }} / K_{\mathrm{m}}$ & $K_{\mathrm{m}}$ & $\boldsymbol{k}_{\text {cat }}$ & $\boldsymbol{k}_{\mathrm{cat}} / K_{\mathrm{m}}$ \\
\hline $1 \mathrm{~B} 10^{\mathrm{a}}$ & 0.4 & 4.3 & 12300 & & N.A. & \\
\hline 1B12 & 0.5 & 1.4 & 2900 & & N.A. & \\
\hline $1 \mathrm{C} 3^{\mathrm{b}}$ & & N.A. & & 0.30 & 0.26 & 850 \\
\hline
\end{tabular}

Activities were determined in $90 \mathrm{mM} \mathrm{KH}_{2} \mathrm{PO}_{4}, 40 \mathrm{mM} \mathrm{KCl}, \mathrm{pH} 7.4,2.3 \mathrm{mM}$ $N A D P^{+}, 37^{\circ} \mathrm{C}$. NA, no activity. Units: $K_{m}(\mu M), k_{c a t}\left(m^{-1}\right), K_{c a t} / K_{m}\left(m M^{-1} m^{-1}\right)$. ${ }^{a}$ Gallego et al. (2007b), 'b Ruiz et al. (2011b).

9-cis-retinaldehyde, especially AKR1C3, which is unique in having a high $k_{\text {cat }}$ value and a catalytic efficiency in the same order as that of AKR1B10 with all-trans-retinaldehyde (Ruiz et al., 2011b).

Some AKR1B enzymes are also active toward ringoxidized retinoids, like all-trans-4-hydroxy, 4-oxo, and 3,4didehydroretinaldehyde (Ruiz et al., 2009). Reminiscent of what is observed with $\mathrm{ADH}, k_{\text {cat }}$ values increase between 4 - and 20 -fold in AKRs with ring-oxidized retinoids in comparison with underivatized retinoids (Martras et al., 2004; Ruiz et al., 2009). These derivatives are involved in degradation pathways, but in some cases they are bioactive compounds which can bind to nuclear receptors. These results suggest that AKR1B enzymes may be potentially involved in these pathways in vivo.

\section{EFFECT OF CRBP-I AND MICROSOMAL MEMBRANES ON RETINOID OXIDOREDUCTASE ACTIVITY}

Cellular retinol binding protein type I is a cytosolic protein with a widespread tissue distribution. Since CRBP-I binds retinol with very high affinity ( $K_{\mathrm{d}}$ for retinol $\approx 0.1 \mathrm{nM}$ ), retinol availability for 
enzymes in a cellular environment is an important issue. Therefore, the activity of AKR1B10 with retinol, along with that of some other oxidoreductases from the MDR and SDR superfamilies, was checked in the presence of CRBP-I (Gallego et al., 2006) by using the HPLC assay. The presence of CRBP-I seriously hampered enzymatic activity with retinol. All the enzymes analyzed could use free retinol as a substrate but not retinol bound to CRBP-I. The small activity found with holo-CRBP-I was attributed to the dissociated free retinol which was in equilibrium with CRBP-I. This point was confirmed for microsomal $\mathrm{RDH}$ by other laboratories (Belyaeva et al., 2005, 2008; Farjo et al., 2011) and suggests that oxidoreductases may have limited access to retinol bound to CRBP-I.

In addition, evidence indicates that a fraction of cellular retinol is associated with membranes. In fact, retinol needs to be transferred to membranes of the endoplasmic reticulum in order to be esterified by LRAT, and most SDR retinol dehydrogenases are microsomal. Thus, the effect of added microsomal membranes on the retinol dehydrogenase activity of $\mathrm{AKR} 1 \mathrm{~B} 10$ and representative enzymes of two other oxidoreductase superfamilies was investigated. Enzyme activity was inhibited in a dose-dependent manner by microsomal membranes (Gallego et al., 2007a) and, in some cases, by adding phospholipid-based liposomes (Farjo et al., 2011). In conclusion, cytosolically located enzymes may not have access to retinol bound to CRBP-I nor to that absorbed into membranes, while microsomal enzymes could use the latter.

Retinaldehyde reductase activity of AKR1B1 and 1B10, side-byside with that of cytosolic ADH and microsomal SDR enzymes, was also analyzed in the presence of CRBP-I (Gallego et al., 2006). Although the enzymes examined only could use free retinaldehyde, they could still function in the presence of CRBP-I because of a higher dissociation constant ( $K_{\mathrm{d}}$ for retinaldehyde $\approx 50 \mathrm{nM}$ ), which results in a significant fraction of free retinaldehyde found in solution (Parés et al., 2008).

\section{STRUCTURAL DETERMINANTS OF RETINALDEHYDE REDUCTASE ACTIVITY IN AKRs}

AKR1B1 is likely one of the best characterized proteins at structural level, with a large number of high quality structures solved and some at unprecedented ultrahigh resolution $(0.66 \AA$; Howard et al., 2004). Many crystallographic structures of AKR1 ternary complexes have been solved using enzyme inhibitors as ligands, mostly because of their pharmacological relevance (Lovering et al., 2004; El-Kabbani and Podjarny, 2007; Barski et al., 2008). In contrast, only one crystal structure of an AKR1B enzyme complex with a substrate or analog has been obtained (AKR1B1-NADPglucose-6-phosphate, PDB 2ACQ) and only few for some AKR1C enzymes. In this latter case, the studies were based on the use of substrates showing low $k_{\text {cat }}$ values, which helped stabilizing the ternary complex (i.e., AKR1C2-NADP-testosterone, PDB 1J96; AKR1C3-NADP-prostaglandin $\mathrm{D}_{2}$, PDB 1RY0). As for retinoid molecules bound to AKR enzymes, structural data are lacking and only have been inferred from docking and molecular dynamics (MD) simulations (Gallego et al., 2007b; Ruiz et al., 2009, 2011a,b). From these crystallographic and modeling studies, the main interacting residues in the cofactor- and substrate-binding sites could be identified. In the active site, the vast majority of AKRs have a catalytic tetrad featuring Asp44, Tyr49, Lys78, and His111 (AKR1B10 numbering). The most variable area in the substrate-binding site between different enzymes is found in loops A (residues 112-136), B (residues 212-226), and C (residues 297-307). Substrate specificity and inhibitor selectivity is mostly determined by the interaction with residues located in these three highly variable loops.

Members of subfamily AKR1A (aldehyde reductase) did not show activity with retinoids. A larger loop C, with an insertion of nine amino acid residues, not present in AKR1B and AKR1C enzymes, could be the determinant for the absence of activity of pig aldehyde reductase (AKR1A2) with retinoids, as it restricts the access of bulky substrates and inhibitors to the cavity (Barski et al., 1996; Crosas et al., 2003).

Regarding the subfamily $1 \mathrm{~B}$, as mentioned above, several AKR1B1 inhibitor complexes have been obtained. In contrast, for AKR1B10, only one three-dimensional structure, the ternary complex AKR1B10-NADP ${ }^{+}$-tolrestat has been solved (PDB 1ZUA; Gallego et al., 2007b). The comparison between AKR1B1 and AKR1B10 structures allowed explaining the difference of 100 times in catalytic efficiency with all-trans-retinaldehyde. MD simulations showed that all-trans-retinaldehyde is a bulky molecule which, in contrast to smaller molecules like tolrestat, interacted through its cyclohexene ring with the outer region of the substrate-binding pocket, especially with loops A and C. The most remarkable amino acid substitutions in residues participating in retinoid binding between $\mathrm{AKR} 1 \mathrm{~B} 1$ and $\mathrm{AKR} 1 \mathrm{~B} 10$ were observed at positions 125 (Leu to Lys) and 304 (Cys to Ser).

Site-directed mutagenesis exchanging the AKR1B10 residues for those of AKR1B1 (K125L and S304C) was performed and the resulting single and double mutant enzymes were kinetically characterized (Table 4). With all-trans-retinaldehyde, the $k_{\text {cat }}$ value of both single mutants decreased more than 10 fold compared to the wild-type enzyme, while the double mutant showed a similar value to that of the low-retinoid activity AKR1B1. The kinetics with DLglyceraldehyde was not affected by the substitutions likely because these residues are located far from where small substrates bind. Thus the $k_{\text {cat }}$ value for DL-glyceraldehyde was similar for all the enzymes listed in Table 4, suggesting a common rate-limiting step, likely cofactor dissociation. In contrast, large differences in the $k_{\text {cat }}$ value with all-trans-retinaldehyde suggest that the rate-limiting

Table 4 | Catalytic constants $\left(k_{\text {cat }}, \min ^{-1}\right.$ ) of AKR1B10, AKR1B10 K125L, and AKR1B10 S304C mutants, and AKR1B1.

\begin{tabular}{lll}
\hline Enzyme & DL-Glyceraldehyde & All-trans-retinaldehyde \\
\hline AKR1B10 & 35 & 27 \\
K125L & 35.6 & 2.0 \\
S304C & 29 & 2.0 \\
K125L/S304C & 28 & 0.12 \\
AKR1B1 & 31 & 0.35 \\
\hline
\end{tabular}

Activities were determined in $0.1 \mathrm{M}$ sodium phosphate, $\mathrm{pH} 7.5,0.2 \mathrm{mM} \mathrm{NADPH}$, $25^{\circ} \mathrm{C}$, with $\mathrm{DL}$-glyceraldehyde, and in $90 \mathrm{mM} \mathrm{KH}_{2} \mathrm{PO}_{4}, 40 \mathrm{mM} \mathrm{KCl}, \mathrm{pH} 7.4,0.5 \mathrm{mM}$ $N A D P H, 37^{\circ} \mathrm{C}$, with all-trans-retinaldehyde, using the HPLC assay. Data from Ruiz et al. (2011a). 
step for this substrate differs between AKR1B1 and AKRB10. It is conceivable that either the chemical step or product release is slower when retinaldehyde is the substrate in AKR1B enzymes, the exception being AKR1B10, which has a similar $k_{\text {cat }}$ value for all-trans-retinaldehyde and DL-glyceraldehyde. MD simulation and kinetics with ring-oxidized retinoids supported this notion, although transient kinetic experiments would be required to confirm it unequivocally (Gallego et al., 2007b; Ruiz et al., 2009, 2011a).

Molecular dynamics simulations showed that binding of alltrans-retinaldehyde to AKR1B10 required Lys125 to swivel toward the solvent, something not required in the other models tested (Figure 2; Gallego et al., 2007b). One interesting finding is that in order to achieve a higher enzyme activity with retinoids, AKR1B enzymes require a hydrophilic group to be present either in the substrate cyclohexene ring or in enzyme residue 125, facilitating proper orientation of substrate for catalysis or product release. When exchanging Ser304 by Cys in AKR1B10, some

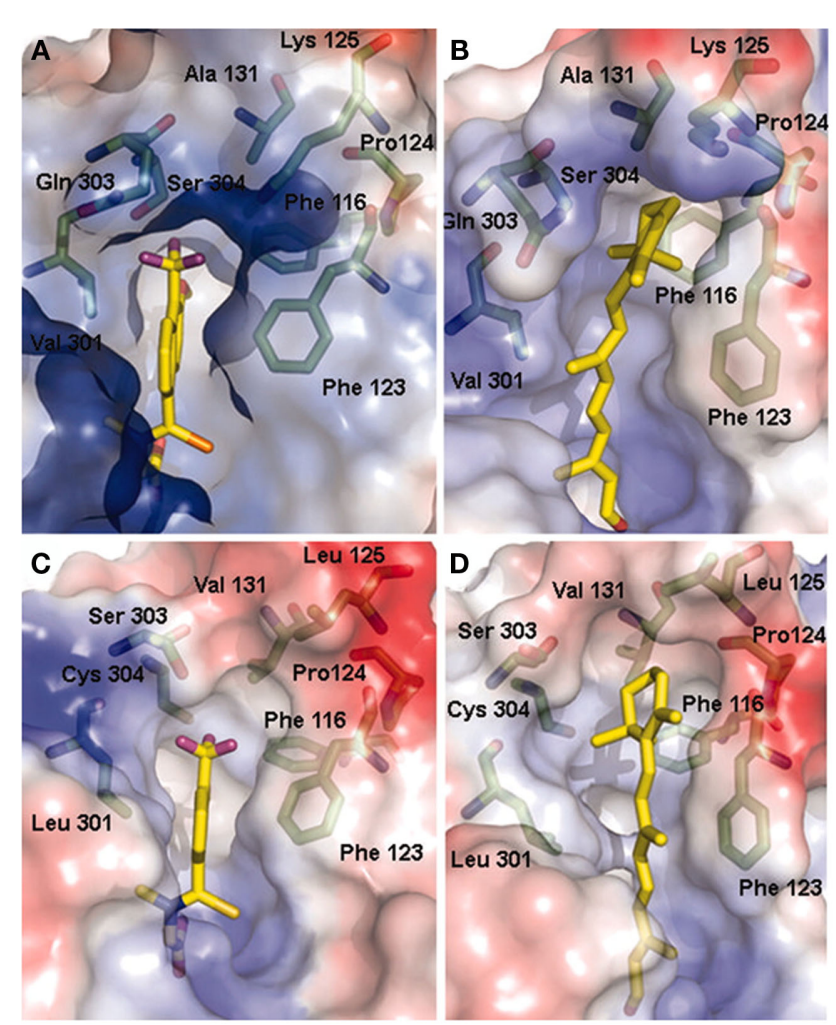

FIGURE 2 | Models of all-trans-retinaldehyde docked into the AKR1B10 and AKR1B1 structures. (A) Tolrestat-binding pocket in the

AKR1B10-NADP+-tolrestat crystal. (B) All-trans-retinaldehyde binding pocket of AKR1B10 predicted by our model. (C) Tolrestat-binding pocket in the AKR1B1-NADP+-tolrestat crystal (PDB entry 2FZD). (D) All-trans-retinaldehyde binding pocket of AKR1B1 predicted by docking and MD. The molecular surface is colored according to the local electrostatic potential as calculated with the program PYMOL (www.pymol.org). Residues around the substrate define a highly hydrophobic and well adjusted pocket, protecting the retinaldehyde molecule from the polar solvent. Reproduced with permission from Gallego et al. (2007b). Copyright@2007, National Academy of Sciences, USA. hydrogen bonds and hydrophobic interactions between loops A and $\mathrm{C}$ of $\mathrm{AKR} 1 \mathrm{~B} 1$ are predicted to be broken. Somehow, structural variations in the $\mathrm{K} 125 \mathrm{~L} / \mathrm{S} 304 \mathrm{C}$ double mutant may have induced protein loop rearrangements and product-protein interaction changes (Ruiz et al., 2011a), which may explain the large decrease in its $k_{\text {cat }}$ value, similar to that of the low-retinoid activity AKR1B1 (Table 4). Thus, Lys125 and Ser304, the latter being unique to $1 \mathrm{~B} 10$ and chicken $1 \mathrm{~B} 12$ (also a highly active retinaldehyde reductase), are major structural determinants for all-transretinaldehyde specificity of 1B10, as assessed by site-directed mutagenesis and molecular dynamics. In summary, retinoid specificity in the $1 \mathrm{~B}$ subfamily seems to be governed by hydrophilic contacts in the outer part of the substrate-binding site and by loop-loop interactions.

As described above, human 1C subfamily members, especially AKR1C3, are predominantly 9-cis-retinaldehyde reductases. AKR1C enzymes have some amino acid insertions at their Nterminal region and also a shorter loop B in the part interacting with the cofactor. This smaller loop makes the chemical step and product release to be more rate-limiting than cofactor dissociation in comparison to $1 \mathrm{~A}$ and $1 \mathrm{~B}$ enzymes (Jin and Penning, 2006; Barski et al., 2008). Binding of retinaldehyde isomers to AKR1C1, a low activity enzyme, and AKR1C3, a high activity enzyme, was compared and the computer models obtained were very similar in their overall structure, but with some subtle changes. Trp227, located in loop B and conserved in the two proteins, adopted different conformations in the complexes, resulting in different loop arrangements. Structural analysis suggested that the variation in the conformation could be due to residue 226, Arg in AKR1C3, and Pro in AKR1C1, resulting in a more rigid and tighter loop B. The importance of this residue was partially supported by a moderate drop in the catalytic efficiency of AKR1C3 R226P and R226Q mutants. Additional structural features might contribute to the $k_{\text {cat }}$ difference between the two enzymes. Probably, the wider and more hydrophilic site of AKR1C3 could facilitate binding of 9-cis-retinaldehyde. The lower activity of AKR1C3 with all-trans-retinaldehyde could also be explained by a distinct loop B conformation in the complex with this isomer, whose different geometry resulted in a positioning similar to that of the AKR1C1:9-cis-retinaldehyde complex (Ruiz et al., 2011b).

\section{BIOLOGICAL ROLE OF AKRS AS RETINALDEHYDE REDUCTASES}

\section{RETINALDEHYDE REDUCTASE ACTIVITY OF AKRS IN CELLULAR MODELS}

Since AKR enzymes had been characterized in vitro as retinaldehyde reductases, their activity was also tested in different cellular models, namely, primary cell cultures as well as tumor cell lines. In order to identify endogenous or transfected AKRs as the origin of retinaldehyde reductase activity, two different experimental approaches were used, i.e., enzyme overexpression and/or the use of enzyme inhibitors.

Primary cultures of human aortic smooth muscle cells, when stimulated to proliferate, overexpressed AKR1B1 and converted $35 \%$ of added retinaldehyde to retinol. This conversion decreased by $40 \%$ when cells were incubated in the presence of tolrestat, an AKR1B1 inhibitor. Therefore, AKR1B1, which typically shows low 
in vitro enzyme activity, acted as a retinaldehyde reductase in a cellular environment, which points out to a significant role in vivo (Gallego et al., 2006).

Monkey kidney COS-1 cells, when transiently expressing AKR1B10, doubled their capacity for all-trans-retinaldehyde reduction (Gallego et al., 2007b). Overexpression of AKR1B10 in human airway epithelial $16 \mathrm{HBE}$ cells treated with retinaldehyde also increased retinol production (Wang et al., 2010). Lastly, human lung adenocarcinoma A549 cells showed a retinaldehyde

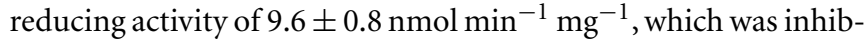
ited by $50 \%$ upon treatment with ponalrestat (an AKR1B1 and AKR1B10 inhibitor; Quinn et al., 2008).

Breast adenocarcinoma MCF-7 cells were used as a model to study retinaldehyde reductase activity of AKR1C enzymes. These cells exhibit very low retinol oxidation activity, down-regulated retinol esterification and low retinaldehyde oxidation. Retinaldehyde reduction was found to be very high and approximately $30 \%$ of this activity was due to AKR1C enzymes, presumably to AKR1C3, as shown by flufenamic acid inhibition (an AKR1C1 and AKR1C3 inhibitor). The reductive metabolism of 9-cisretinaldehyde was less significant, although AKR1C3 and AKR1C1 were responsible for approximately $90 \%$ of this activity (Ruiz et al., 2011b).

As for the oxidizing activity, transfection in COS-1 cells with AKR1B10 did not increase conversion of externally added retinol to retinaldehyde (Gallego et al., 2007b) and AKR1C3 inhibition had no effect on the retinol conversion in MCF-7 cells (Ruiz et al., 2011b). Thus, both AKR1B and AKR1C enzymes could not function as retinol dehydrogenases in cell culture. These results were expected since, in metabolically active cells, NADP is mostly found in its reduced state and therefore reductive metabolism by NADPdependent enzymes is favored over oxidative reactions (Barski et al., 2008). A similar finding had been previously described in COS- 1 cells, where transient transfection of AKR1C enzymes indicated that they function as ketosteroid reductases (Penning et al., 2004).

Overall, these studies using different cellular models confirm that the retinaldehyde reductase activity of human AKRs may have an in vivo role in the RA biosynthetic pathway.

\section{EFFECT OF AKR ACTIVITY ON RA SIGNALING THROUGH PRE-RECEPTOR REGULATION}

Having demonstrated that AKRs are able to decrease in vitro and cellular retinaldehyde levels, we explored whether their retinaldehyde reductase activity might also deplete RA levels thus affecting RA signaling. For this purpose, HeLa cells were transiently cotransfected with an AKR expression plasmid and a RARE reporter plasmid, and treated with either all-trans or 9-cis-retinol. Overexpression of each of AKR1B1, 1B10, 1C3, and 1C4 decreased both all-trans-and 9-cis-RA-dependent trans-activation, meaning a lower amount of RA being produced due to their retinaldehyde reductase activity (Ruiz et al., 2009, 2011b). This result implies that AKR1B and $1 C$ enzymes are part of a fine tuning regulating system of RA biosynthesis, carried out by proteins from different superfamilies, such as AKR, MDR, and SDR, and described earlier in this review. Overall this indicates that AKR enzymes may contribute to pre-receptor down-regulation of RAR and RXR transcriptional activity, which could lead to cell proliferation and increased cancer risk in target tissues.

It is well known that these enzymes and other members of the human AKR1A, 1B, and 1D subfamilies are able to use as substrates lipophilic molecules other than retinoids, including steroids, prostaglandins, and polycyclic aromatic hydrocarbons. Interestingly, these compounds or their derivatives act as ligands of a wide variety of nuclear hormone receptors (Penning and Drury, 2007), which suggests a biological function in the regulation at prereceptor level. Consequently, the retinaldehyde reductase activity of $\mathrm{AKR} 1 \mathrm{~B}$ and $1 \mathrm{C}$ enzymes can now be added to this complex regulatory interplay.

\section{ROLE OF AKR1C3 IN THE CONTROL OF 9-cis-RA LEVELS}

The 9-cis isomer of RA binds to both RAR and RXR with high affinity in vitro, and has diverse pharmacological actions which are distinct from those of all-trans-RA. Intensive analytical research in quantifying RA isomers had not detected 9-cis-RA in serum and in a variety of tissues, until the recent identification of this isomer in pancreas, where it plays a role in regulation of glucose-stimulated insulin secretion (Kane et al., 2010; Kane, 2012). About $80 \%$ of pancreatic 9-cis-RA is concentrated in $\beta$-cells, which represent less than $5 \%$ of the total pancreatic cell population. This indicates a very discrete cellular localization of this isomer. It is possible that 9-cis-RA may only be present in a local cell population in other tissues, and thus dilution of the isomer in the homogenate of the whole tissue may preclude its detection. A source of 9-cis-RA could be 9-cis-retinol, which has been detected in pancreas and other tissues (Kane, 2012), while enzymes oxidizing 9-cis-retinol and 9-cis-retinaldehyde are widespread (Table 5). In addition, 9cis carotenoids found in the diet can produce 9-cis-retinaldehyde by the action of BCO1 (Kane, 2012). Levels of 9-cis-retinaldehyde would be controlled by the action of oxidoreductases. In general retinaldehyde oxidoreductases are more specific for the all-trans than for the 9-cis isomer (Table 5), except for several AKR enzymes, especially AKR1C3. The robust AKR1C3 activity with the 9-cis form is comparable or higher than that of the members of other enzyme superfamilies, supporting a role in the control of 9-cis-RA signaling. Specificity for the 9-cis over the all-trans isomer has also been observed in other enzymes, such as RDH5 (Mertz et al., 1997) and ALDH8A1 (Lin and Napoli, 2000).

\section{ROLE OF CYTOSOLIC AKRS IN SUBCELLULAR RETINALDEHYDE METABOLISM}

As discussed above, in vitro and cellular studies indicate that AKRs could be involved in the reduction of retinaldehyde to retinol. Furthermore, this activity could modulate RA synthesis, confirming that the control of retinaldehyde levels is essential in the regulation of RA function.

Available evidence supports cellular compartmentalization of retinoid metabolism. The enzymes involved in RA synthesis are localized in different subcellular compartments. In addition, the low solubility of retinol and retinaldehyde in water also influences their distribution in the cell. In the cytoplasm, retinol is tightly bound to CRBP-I (Napoli, 1999). Retinol is also found in free form incorporated into endoplasmic reticulum membranes, which is supported by the observation that CRBP-I can transfer retinol 
Table 5 | Properties of human retinaldehyde oxidoreductases with reported kinetic constants.

\begin{tabular}{|c|c|c|c|c|c|c|c|c|}
\hline \multirow[t]{3}{*}{ Enzyme } & \multicolumn{4}{|c|}{ Substrate } & \multirow{3}{*}{$\begin{array}{l}\text { Reaction } \\
\text { (cofactor) }\end{array}$} & \multirow{3}{*}{$\begin{array}{l}\text { Subcellular } \\
\text { localization }\end{array}$} & \multirow[t]{3}{*}{ Tissue distribution } & \multirow[t]{3}{*}{ Reference } \\
\hline & \multicolumn{2}{|c|}{ All-trans-Ral } & \multicolumn{2}{|c|}{ 9-cis-Ral } & & & & \\
\hline & $k_{\text {cat }} / K_{\mathrm{m}}$ & $V_{\max } / K_{\mathrm{m}}$ & $k_{\text {cat }} / K_{\mathrm{m}}$ & $V_{\max } / K_{m}$ & & & & \\
\hline AKR1B1 & 320 & 8.3 & 1500 & 45 & & & Widespread & $\begin{array}{l}\text { Gallego et al. (2007b), } \\
\text { Grimshaw and Mathur (1989) }\end{array}$ \\
\hline AKR1B10 & 45000 & 1200 & 1300 & 33 & & & $\begin{array}{l}\text { Small intestine, adrenal } \\
\text { gland, colon } \gg \text { liver, } \\
\text { thymus }\end{array}$ & $\begin{array}{l}\text { Gallego et al. (2007b), } \\
\text { Hyndman and Flynn (1998), } \\
\text { Cao et al. (1998) }\end{array}$ \\
\hline AKR1C1 & L.A. & & 370 & 10 & $\begin{array}{l}\text { Reduction } \\
\text { (NADPH) }\end{array}$ & Cytosolic & $\begin{array}{l}\text { Lung, liver } \gg \text { testis, } \\
\text { mammary gland }\end{array}$ & $\begin{array}{l}\text { Ruiz et al. (2011b), Penning } \\
\text { et al. (2000) }\end{array}$ \\
\hline AKR1C3 & 430 & 11 & 32,500 & 850 & & & $\begin{array}{l}\text { Mammary gland, } \\
\text { prostate } \gg \text { liver, lung }\end{array}$ & $\begin{array}{l}\text { Ruiz et al. (2011b), Penning } \\
\text { et al. (2000) }\end{array}$ \\
\hline AKR1C4 & 790 & 20 & 500 & 13 & & & Liver & $\begin{array}{l}\text { Ruiz et al. (2011b), Penning } \\
\text { et al. (2000) }\end{array}$ \\
\hline $\mathrm{RDH} 11$ & N.D. & 4200 & N.D. & $8.4^{*}$ & & & Widespread & Belyaeva et al. (2003), \\
\hline $\mathrm{RDH} 12$ & 900000 & 25000 & 100000 & 2800 & $\begin{array}{l}\text { Reduction } \\
\text { (NADPH) }\end{array}$ & Microsomal & $\begin{array}{l}\text { Retina } \gg>\text { kidney }> \\
\text { pancreas } \gg \text { other }\end{array}$ & $\begin{array}{l}\text { Kedishvili et al. (2002) } \\
\text { Belyaeva et al. (2005) }\end{array}$ \\
\hline $\mathrm{RDH} 14$ & N.D. & $340^{*}$ & N.D. & & & & Widespread & Belyaeva and Kedishvili (2002) \\
\hline ALDH1A1 & N.D. & $3700,4.2^{* *}$ & N.D. & $5.6 * *$ & & & Widespread & $\begin{array}{l}\text { Yoshida et al. (1992), Xi and } \\
\text { Yang (2008), King and Holmes } \\
\text { (1998), Gagnon et al. (2002) }\end{array}$ \\
\hline ALDH1A2 & N.D. & $6.5^{\dagger}$ & N.D. & $1.2^{\dagger}$ & $\begin{array}{l}\text { Oxidation } \\
\left(\mathrm{NAD}^{+}\right)\end{array}$ & Cytosolic & $\begin{array}{l}\text { Testis, ovary }>\text { pancreas, } \\
\text { placenta } \gg \text { lung, } \\
\text { intestine, liver }\end{array}$ & $\begin{array}{l}\text { Xi and Yang (2008), Gagnon } \\
\text { et al. (2002) }\end{array}$ \\
\hline ALDH1A3 & 1170000 & 5000 & N.D. & & & & Widespread & $\begin{array}{l}\text { Xi and Yang (2008), Graham } \\
\text { et al. (2006) }\end{array}$ \\
\hline ALDH8A1 & L.A. ${ }^{\#}$ & & N.D. & $0.23^{\#}$ & & & Kidney and liver & Lin and Napoli (2000) \\
\hline
\end{tabular}

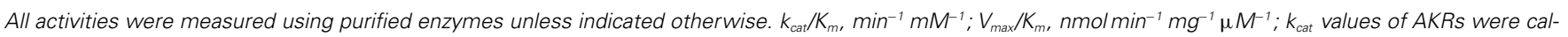

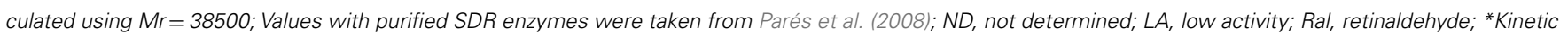

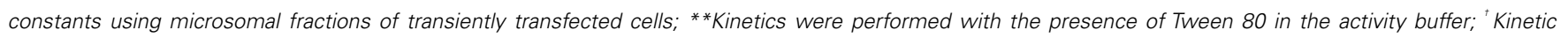
constants of mouse enzyme; "Kinetic constants using whole cell lysates of transiently transfected cells.

to phospholipid membranes (Herr et al., 1999). LRAT and REH are both membrane-bound enzymes and LRAT-enriched microsomal fraction uses efficiently retinol bound to membranes or to CRBP-I (Ghyselinck et al., 1999; Gallego et al., 2006). As we have previously seen, the human enzymes involved in the redox transformations of retinol and retinaldehyde are not active with the CRBP-I-retinol complex, but only with free retinol (Gallego et al., 2006; Farjo et al., 2011). In fact, CRBP-I is not needed for retinol oxidation since mice lacking CRBP-I did not exhibit decreased RA synthesis but instead they had greatly reduced their stores of liver retinyl esters (Ghyselinck et al., 1999). Interestingly, double transgenic mice lacking CRBP-I and ADH recovered normal levels of retinyl esters, meaning that CRBP-I might protect free retinol from being oxidized to retinaldehyde and converted to RA. Interestingly, mouse loss-of-function models indicate that the highly active cytosolic ADH show a minor role in RA synthesis during embryonic development, while the less active microsomal RDH10 (an
SDR member, also inactive with CRBP-I-bound retinol) is essential (Farjo et al., 2011; Kumar et al., 2012). This suggests that RDH10, but not $\mathrm{ADH}$, has access to free retinol absorbed into the membrane, and that the physiological oxidation of retinol occurs predominantly in a membrane-bound cellular compartment (Farjo et al., 2011).

As opposed to retinol, retinaldehyde metabolism has distinct localization features. As we have discussed previously, CRBP-I binds less tightly retinaldehyde (Gallego et al., 2006; Kane et al., 2011), which can be more easily released to its free form than retinol in the cytoplasm. A physiological implication of this fact is that the presence of CRBP-I appears to favor retinaldehyde metabolism over that of retinol oxidation in the cytosol. Oxidation to RA is a cytosolic step since the four ALDH involved (1A1, 1A2, $1 \mathrm{~A} 3$, and $8 \mathrm{~A} 1)$ are soluble proteins. Interestingly, although additional ALDH are localized in other subcellular compartments (e.g., endoplasmic reticulum, mitochondria, or peroxisomes), they are 
not active with retinaldehyde. In contrast, retinaldehyde reduction could be catalyzed either by microsomal SDR or by the cytosolic AKRs. The contribution of each enzyme, and the direction (oxidation or reduction) of the reaction, will depend on its amount in a specific tissue in a precise moment during fetal development or adult life, and on its kinetic properties. Table 5 lists the kinetic and localization properties of major enzymes of retinaldehyde redox transformations. Although comparison of kinetic constants should be done with caution because of different methodologies used, it is apparent that SDR and ALDH are the most efficient enzymes. Using knockout animals, it has been well demonstrated that the three most active ALDH involved are essential for normal embryonic development of mice (Farjo et al., 2011; Kumar et al., 2012). It is also clear that AKR1B10 and AKR1C3 exhibit remarkable efficiencies, comparable to those of enzymes from the other superfamilies. Thus, in tissues with increased expression, either normal tissues or in the pathological conditions discussed below, participation of AKR1B10 and AKR1C3 in the control of retinaldehyde levels could be relevant, which would directly affect the RA signaling pathway.

In summary, collected data situates the first step of RA biosynthesis (retinol to retinaldehyde) mainly in the membrane of endoplasmic reticulum, while the second step (retinaldehyde oxidation) is cytosolic. Finally, retinaldehyde reduction, which regulates the flow of RA synthesis, can happen in either subcellular compartment, with the likely contribution of cytosolic AKRs.

\section{PUTATIVE FUNCTION OF AKRS IN THE METABOLISM OF DIETARY PROVITAMIN A CAROTENOIDS}

Dietary carotenoids are a major source of vitamin A metabolites. In humans, about one half of absorbed $\beta$-carotene is cleaved in the intestinal mucosa by BCO1 to yield two molecules of retinaldehyde. This is then reduced to retinol by poorly characterized reductases, esterified, and the resulting retinyl ester incorporated into chylomicrons. Intact carotenoids can be directly incorporated into chylomicrons and delivered to the liver, and in association with lipoproteins can be also taken up by extrahepatic tissues (Harrison, 2012; Lobo et al., 2012). BCO1 is abundant in intestine and liver, but it is also expressed in a variety of tissues in the embryo and adult, suggesting that local specific conversion of $\beta$-carotene may contribute to retinoid metabolism in peripheral tissues (Lobo et al., 2012). AKR1B10 and other AKRs are also present in intestine and in several tissues (Table 5), and could have a role in the reduction of retinaldehyde produced by the BCO1 action. Furthermore, the cytosolic localization of the BCO1 catalyzed reaction may favor the participation of either AKRs or ALDH in the metabolic fate of retinaldehyde.

\section{ROLE OF RETINALDEHYDE REDUCTASE ACTIVITY OF AKRs IN PROLIFERATION AND TUMORIGENESIS}

Upregulation of some AKR1 enzymes in different types of cancer has been widely reported (reviewed in Ruiz et al., 2009, 2011b). AKR1B10 was initially identified as a protein expressed in hepatocellular carcinoma and its mRNA was also found elevated in a number of cancer cell lines, especially in non-small cell lung cancer and adenocarcinoma (Zeindl-Eberhart et al., 2004; Fukumoto et al., 2005). AKR1B1 has been shown to be involved in colon carcinomas (Tammali et al., 2006). AKR1C3 was overexpressed in a wide variety of tumors, including breast and prostate cancer, either in an hormone-dependent or independent manner (Penning and Byrns, 2009) and leukemia (Desmond et al., 2003).

Generally, the induction of AKR1 enzymes could be explained as a part of the cellular defense response against oxidative stress (Jin and Penning, 2007). Tobacco components and other xenobiotics generate reactive oxygen species which induce AKR1 enzymes in their role as phase I drug-metabolizing enzymes (Figure 3). Indeed, $A K R 1 B 1, A K R 1 B 10$, and $A K R 1 C 1-A K R 1 C 3$ belong to the battery of genes regulated by antioxidant response elements via the Nrf2-Keap-1 complex in humans (Jin and Penning, 2007; Penning and Lerman, 2008; MacLeod et al., 2009; Ebert et al., 2011). AKR1 enzymes, in some cases, contribute to chemotherapeutic drug resistance, which could be rationalized by a direct action through enzymatic activity in the case of carbonyl-bearing compounds, i.e., daunorubicin (Novotna et al., 2008; Verma et al., 2008; Zhong et al., 2011), or indirectly, by reducing oxidative stress generated by these agents (Deng et al., 2004). Consequently, AKR1 enzyme inhibitors could be useful since they would be able to enhance the therapeutic efficacy of anticancer drugs by preventing chemoresistance (Jin and Penning, 2007; Martin and Maser, 2009; Wang et al., 2009; Shen et al., 2011).

A putative mechanism by which the activity of AKR1 enzymes could promote tumor growth is the conversion of retinaldehyde to retinol which would provoke RA deprivation and blockage of its differentiating effect, promoting cell proliferation, and fostering tumorigenesis (Figure 3). According to the model for retinoid pre-receptor metabolism and regulation in target tissues, CRBP-I acts favoring retinol storage into membranes and because of its high affinity for retinol and low one for retinaldehyde restricts the availability of the first and allows retinaldehyde reductases to display their activity (Parés et al., 2008). Overexpression of AKR1 enzymes found in some cancers would favor retinaldehyde reduction (Penning, 2005). In fact, lung adenocarcinoma cell line A549 possesses a robust retinaldehyde reductase activity, due mostly to AKR1B10 (and to AKR1B1 to a lesser extent; Quinn et al., 2008).

Regarding AKR1B10, due to its high catalytic efficiency with all-trans-retinaldehyde, the importance of the RA-related effect on tumorigenesis is a strong possibility. RA is a crucial factor in airway epithelial differentiation and its local deficiency could promote carcinogenesis of the airway epithelium. Upregulation of AKR1B10 may be an early event in carcinogenesis, as its expression is elevated in squamous metaplasia and precancerous lesions of non-small cell lung carcinoma. This is why it has been suggested as an early detection marker and treatment target for non-small cell lung carcinoma (Fukumoto et al., 2005). Also, AKR1B10 is a smoking-responsive gene, and its upregulation is not limited to squamous metaplasia and cancer tissues but occurs in the airway epithelium in response to smoking (even healthy smokers show induction of AKR1B10 expression). AKR1B10 high activity would also explain the failure of $\beta$-carotene supplementation to reduce lung cancer risk, because AKR1B10 would prevent RA generation (Penning, 2005; Quinn et al., 2008).

AKR1C3 induction is related to hormone-dependent breast and prostate cancer and now with a putative relevant role in cancer 


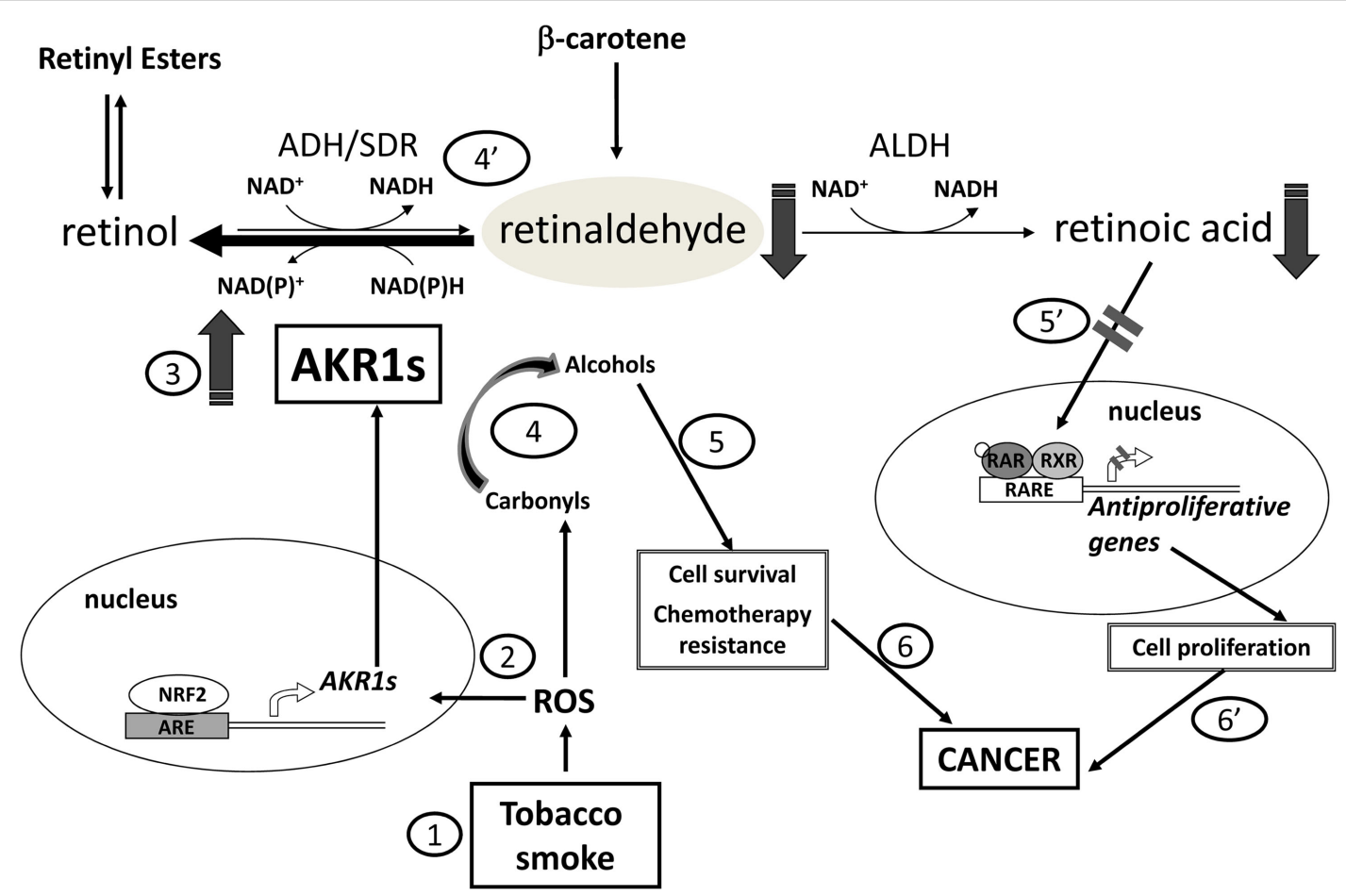

FIGURE 3 | Relationship of AKR1 enzymes with carcinogenesis at different levels. Firstly, reactive oxygen species (ROS), such as these generated by tobacco smoke, trigger the expression of some AKR1 enzymes (steps 1, 2, 3). Subsequently, activity of AKR1 enzymes with retinaldehyde provokes retinoic acid (RA) deprivation blocking its differentiating effect (steps $4^{\prime}$ and $5^{\prime}$ ), and favoring cell proliferation.
Besides, AKR1 enzymes participate in the detoxification of lipid peroxidation aldehydes and can also metabolize various antitumoral agents bearing a carbonyl group (step 4). Through these activities, the enzymes promote cell survival and chemotherapeutic drug resistance (step 5). Overall, induction of AKR1 enzymes foster tumorigenesis (steps 6 and $\left.6^{\prime}\right)$. related to RA signaling. Recently, cell proliferation was studied in human promyelocytic leukemia HL-60 cells, which endogenously express AKR1C3 (Ruiz et al., 2011b). It was demonstrated that the pro-proliferative action of AKR1C3 was mediated in part by the RA signaling pathway. Specifically, the addition of lithocholic acid (an AKR1C3 inhibitor) enhanced the antiproliferative effect of 9cis-retinol. The inhibition of AKR1C3 could cause an increased flow in the synthesis of 9-cis-RA and, consequently, a lower proliferation rate. The fact that HL-60 cells possess the enzymatic machinery to produce RA, as well as RAR and RXR, makes plausible that the observed effect was due to the action of 9-cis-RA. The use of an RAR antagonist restored the proliferation levels obtained with 9-cis-retinol alone, confirming that the observed effects were mediated via the RA signaling pathway.

Desmond et al. (2003), by using the same HL-60 model, had previously shown that AKR1C3 inhibition caused cell differentiation and increased synthesis of 15 -deoxy- $\Delta^{12,14}$-prostaglandin $\mathrm{J}_{2}$ $\left(15 \Delta-\mathrm{PG}_{2}\right)$, a PPAR $\gamma$ ligand. Taken together these results indicate that induced AKR1C3 activity may deplete the agonists of both PPAR $\gamma$ and RAR, resulting in cell proliferation and tumor progression. Therefore, an intriguing possibility arises: AKR1C3 may regulate antiproliferative signaling mediated by heterodimeric complexes between PPAR $\gamma$ and RXR and thus enzyme inhibitors could increase the 9-cis-retinol/RA antiproliferative effect, with a potential use in leukemia treatment (Figure 4; Ruiz et al., 2011b).

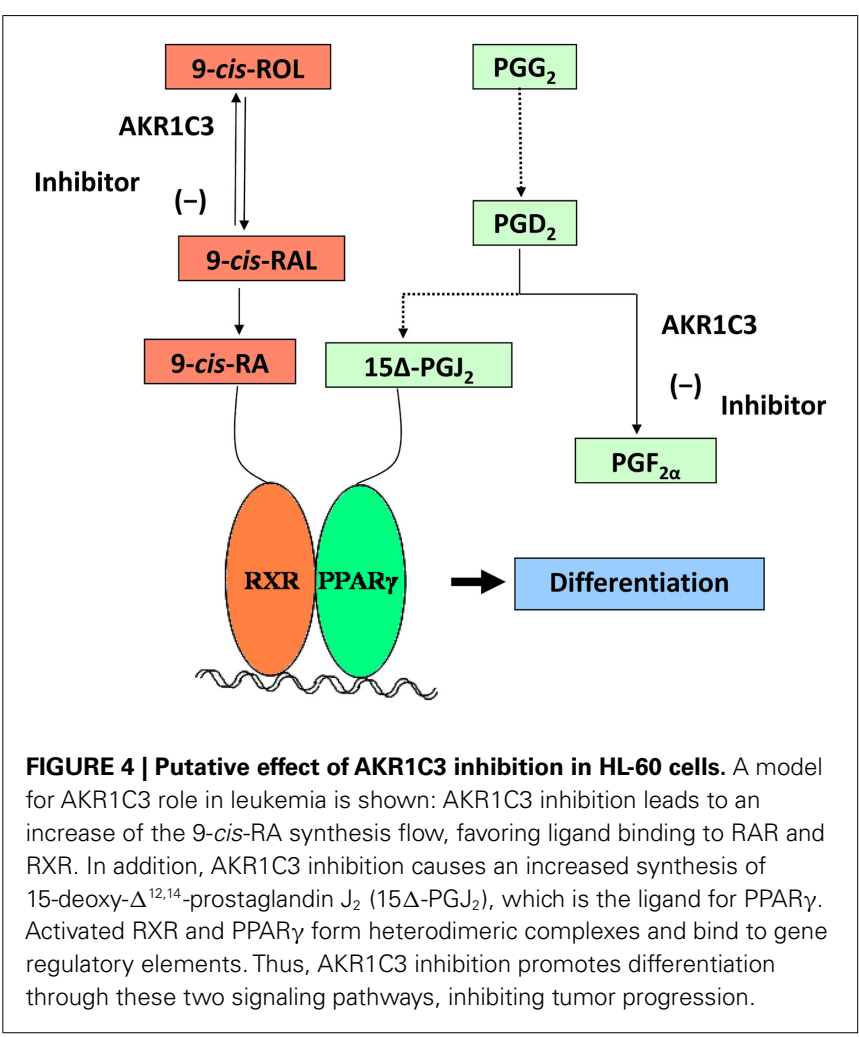


In conclusion, accumulated experimental evidence with AKRs and retinoids adds further support to the previous notion that enzymatic activity of AKRs plays a role in the hormonal regulation of cell proliferation at pre-receptor level. In addition, the AKR-mediated modulation of RXR and their ability to form heterodimeric complexes with other nuclear receptors raises the possibility of cross-talk between different signaling pathways. Unbalanced AKR expression may lead to dedifferentiation and increased cancer risk in target tissues, and provides a rationale for the design

\section{REFERENCES}

Barski, O. A., Gabbay, K. H., and Bohren, K. M. (1996). The Cterminal loop of aldehyde reductase determines the substrate and inhibitor specificity. Biochemistry 35, 14276-14280.

Barski, O. A., Tipparaju, S. M., and Bhatnagar, A. (2008). The aldo-keto reductase superfamily and its role in drug metabolism and detoxification. Drug Metab. Rev. 40, 553-624.

Belyaeva, O. V., Johnson, M. P., and Kedishvili, N. Y. (2008). Kinetic analysis of human enzyme RDH10 defines the characteristics of a physiologically relevant retinol dehydrogenase. J. Biol. Chem. 283, 20299-20308.

Belyaeva, O. V., and Kedishvili, N. Y. (2002). Human pancreas protein 2 (PAN2) has a retinal reductase activity and is ubiquitously expressed in human tissues. FEBS Lett. 531, 489-493.

Belyaeva, O. V., Korkina, O. V., Stetsenko, A. V., Kim, T., Nelson, P. S., and Kedishvili, N. Y. (2005). Biochemical properties of purified human retinol dehydrogenase 12 (RDH12): catalytic efficiency toward retinoids and C9 aldehydes and effects of cellular retinol-binding protein type I (CRBPI) and cellular retinaldehyde-binding protein (CRALBP) on the oxidation and reduction of retinoids. Biochemistry 44, 7035-7047.

Belyaeva, O. V., Stetsenko, A. V., Nelson, P., and Kedishvili, N. Y. (2003). Properties of short-chain dehydrogenase/reductase RalR1: characterization of purified enzyme, its orientation in the microsomal membrane, and distribution in human tissues and cell lines. Biochemistry 42, 14838-14845.

Blomhoff, R., and Blomhoff, H. K. (2006). Overview of retinoid metabolism and function. J. Neurobiol. 66, 606-630.

Cao, D., Fan, S. T., and Chung, S. S. (1998). Identification and characterization of a novel human aldose reductase-like gene. J. Biol. Chem. 273, 11429-11435.
Crosas, B., Cederlund, E., Torres, D., Jörnvall, H., Farrés, J., and Parés, X. (2001). A vertebrate aldoketo reductase active with retinoids and ethanol. J. Biol. Chem. 276, 19132-19140.

Crosas, B., Hyndman, D. J., Gallego, O., Martras, S., Parés, X., Flynn, T. G., and Farrés, J. (2003). Human aldose reductase and human small intestine aldose reductase are efficient retinal reductases: consequences for retinoid metabolism. Biochem. J. 373, 973-979.

Deng, H. B., Adikari, M., Parekh, H. K., and Simpkins, H. (2004). Ubiquitous induction of resistance to platinum drugs in human ovarian, cervical, germ-cell and lung carcinoma tumor cells overexpressing isoforms 1 and 2 of dihydrodiol dehydrogenase. Cancer Chemother. Pharmacol. 54, 301-307.

Desmond, J. C., Mountford, J. C., Drayson, M. T., Walker, E. A., Hewison, M., Ride, J. P., Luong, Q. T., Hayden, R. E., Vanin, E. F., and Bunce, C. M. (2003). The aldo-keto reductase AKR1C3 is a novel suppressor of cell differentiation that provides a plausible target for the noncyclooxygenase-dependent antineoplastic actions of nonsteroidal antiinflammatory drugs. Cancer Res. 63, 505-512.

Díez-Dacal, B., Gayarre, J., Gharbi, S., Timms, J. F., Coderch, C., Gago, F., and Pérez-Sala, D. (2011). Identification of aldo-keto reductase AKR1B10 as a selective target for modification and inhibition by prostaglandin A(1): implications for antitumoral activity. Cancer Res. 71, 4161-4171.

Ebert, B., Kisiela, M., Wsol, V., and Maser, E. (2011). Proteasome inhibitors MG-132 and bortezomib induce AKR1C1, AKR1C3, AKR1B1, and AKR1B10 in human colon cancer cell lines SW-480 and HT-29. Chem. Biol. Interact. 191, 239-249.

El-Kabbani, O., and Podjarny, A. (2007). Selectivity determinants of the aldose and aldehyde reductase inhibitor-binding sites. Cell. Mol. Life Sci. 64, 1970-1978. of AKR inhibitor-based drugs. The structural determinants, here reported, of the unique retinaldehyde specificity of AKR1B10 and 1C3, the most relevant AKRs in cancer generation, may facilitate the finding of selective inhibitors with therapeutic interest.

\section{ACKNOWLEDGMENTS}

This work was supported by grants from the Spanish Dirección General de Investigación (BFU2008-02945 and BFU2011-24176) and Generalitat de Catalunya (2009 SGR 795).
Endo, K., Fukui, M., Mishima, M., and Watanabe, K. (2001). Metabolism of vitamin A affected by prostaglandin $F$ synthase in contractile interstitial cells of bovine lung. Biochem. Biophys. Res. Commun. 287, 956-961.

Endo, S., Matsunaga, T., Fujita, A., Tajima, K., El-Kabbani, O., and Hara, A. (2010a). Rat aldose reductaselike protein (AKR1B14) efficiently reduces the lipid peroxidation product 4-oxo-2-nonenal. Biol. Pharm. Bull. 33, 1886-1890.

Endo, S., Matsunaga, T., Kuragano, T., Ohno, S., Kitade, Y., Tajima, K., ElKabbani, O., and Hara, A. (2010b). Properties and tissue distribution of a novel aldo-keto reductase encoding in a rat gene (Akrlb10). Arch. Biochem. Biophys. 503, 230-237.

Endo, S., Matsunaga, T., Horie, K., Tajima, K., Bunai, Y., Carbone, V., El-Kabbani, O., and Hara, A. (2007). Enzymatic characteristics of an aldo-keto reductase family protein (AKR1C15) and its localization in rat tissues. Arch. Biochem. Biophys. 465, 136-147.

Endo, S., Matsunaga, T., Mamiya, H., Hara, A., Kitade, Y., Tajima, K., and El-Kabbani, O. (2009). Characterization of a rat NADPH-dependent aldo-keto reductase (AKR1B13) induced by oxidative stress. Chem. Biol. Interact. 178, 151-157.

Farjo, K. M., Moiseyev, G., Nikolaeva, O., Sandell, L. L., Trainor, P. A., and Ma, J. X. (2011). RDH10 is the primary enzyme responsible for the first step of embryonic Vitamin A metabolism and retinoic acid synthesis. Dev. Biol. 357, 347-355.

Fukumoto, S., Yamauchi, N., Moriguchi, H., Hippo, Y., Watanabe, A., Shibahara, J., Taniguchi, H., Ishikawa, S., Ito, H., Yamamoto, S., Iwanari, H., Hironaka, M., Ishikawa, Y., Niki, T., Sohara, Y., Kodama, T., Nishimura, M., Fukayama, M., Dosaka-Akita, H., and Aburatani, H. (2005). Overexpression of the aldo-keto reductase family protein AKR1B10 is highly correlated with smokers' nonsmall cell lung carcinomas. Clin. Cancer Res. 11, 1776-1785.
Gagnon, I., Duester, G., and Bhat, P. V. (2002). Kinetic analysis of mouse retinal dehydrogenase type-2 (RALDH2) for retinal substrates. Biochim. Biophys. Acta 1596, 156-162.

Gallego, O., Belyaeva, O. V., Porté, S., Ruiz, F. X., Stetsenko, A. V. Shabrova, E. V., Kostereva, N. V., Farrés, J., Parés, X., and Kedishvili, N. Y. (2006). Comparative functional analysis of human medium-chain dehydrogenases, short-chain dehydrogenases/reductases and aldoketo reductases with retinoids. Biochem. J. 399, 101-109.

Gallego, O., Belyaeva, O. V., Porté, S., Ruiz, F. X., Stetsenko, A. V., Shabrova, E. V., Kostereva, N. V., Martras, S., Parés, X., Kedishvili, N. Y., and Farrés, J. (2007a). "Kinetic analysis of SDRs, ADHs and AKRs toward free and CRBPI-bound retinoids: effect of tween-80 and microsomal membranes," in Enzymology and Molecular Biology of Carbonyl Metabolism 13, eds H. Weiner, R. Lindahl, E. Maser, and B. Plapp (West Lafayette, IN: Purdue University Press), 144-151.

Gallego, O., Ruiz, F. X., Ardèvol, A., Domínguez, M., Álvarez, R., De Lera, A. R., Rovira, C., Farrés, J. Fita, I., and Parés, X. (2007b). Structural basis for the high alltrans-retinaldehyde reductase activity of the tumor marker AKR1B10. Proc. Natl. Acad. Sci. U.S.A. 104, 20764-20769.

Ghyselinck, N. B., Bavik, C., Sapin, V., Mark, M., Bonnier, D., Hindelang, C., Dierich, A., Nilsson, C. B., Hakansson, H., Sauvant, P., AzaisBraesco, V., Frasson, M., Picaud, S., and Chambon, P. (1999). Cellular retinol-binding protein I is essential for vitamin A homeostasis. EMBO J. 18, 4903-4914.

Gough, W. H., Vanooteghem, S., Sint, T., and Kedishvili, N. Y. (1998). cDNA cloning and characterization of a new human microsomal NAD+dependent dehydrogenase that oxidizes all-trans-retinol and 3alphahydroxysteroids. J. Biol. Chem. 273, 19778-19785. 
Graham, C. E., Brocklehurst, K., Pickersgill, R. W., and Warren, M. J. (2006). Characterization of retinaldehyde dehydrogenase 3 . Biochem. J. 394, 67-75.

Grimshaw, C. E., and Mathur, E. J. (1989). Immunoquantitation of aldose reductase in human tissues. Anal. Biochem. 176, 66-71.

Harrison, E. H. (2012). Mechanisms involved in the intestinal absorption of dietary vitamin A and provitamin A carotenoids. Biochim. Biophys. Acta 1821, 70-77.

Herr, F. M., Li, E., Weinberg, R. B., Cook, V. R., and Storch, J. (1999). Differential mechanisms of retinoid transfer from cellular retinol binding proteins types I and II to phospholipid membranes. J. Biol. Chem. 274, 9556-9563.

Hollander, D., and Muralidhara, K. S. (1977). Vitamin A1 intestinal absorption in vivo: influence of luminal factors on transport. Am. J. Physiol. 232, E471-E477.

Howard, E. I., Sanishvili, R., Cachau, R. E., Mitschler, A., Chevrier, B., Barth, P., Lamour, V., Van Zandt, M., Sibley, E., Bon, C., Moras, D., Schneider, T. R., Joachimiak, A., and Podjarny, A. (2004). Ultrahigh resolution drug design I: details of interactions in human aldose reductaseinhibitor complex at 0.66 A. Proteins $55,792-804$.

Hyndman, D. J., and Flynn, T. G. (1998). Sequence and expression levels in human tissues of a new member of the aldo-keto reductase family. Biochim. Biophys. Acta 1399, 198-202.

Jez, J. M., Flynn, T. G., and Penning, T. M. (1997). A new nomenclature for the aldo-keto reductase superfamily. Biochem. Pharmacol. 54, 639-647.

Jin, Y., and Penning, T. M. (2006). Multiple steps determine the overall rate of the reduction of 5alpha-dihydrotestosterone catalyzed by human type 3 3alphahydroxysteroid dehydrogenase: implications for the elimination of androgens. Biochemistry 45, 13054-13063.

Jin, Y., and Penning, T. M. (2007). Aldo-keto reductases and bioactivation/detoxication. Annu. Rev. Pharmacol. Toxicol. 47, 263-292.

Joshi, A., Rajput, S., Wang, C., Ma, J., and Cao, D. (2010). Murine aldoketo reductase family 1 subfamily B: identification of AKR1B8 as an ortholog of human AKR1B10. Biol. Chem. 391, 1371-1378.

Kane, M. A. (2012). Analysis, occurrence, and function of 9-cis-retinoic acid. Biochim. Biophys. Acta 1821, 10-20.

Kane, M. A., Bright, F. V., and Napoli, J. L. (2011). Binding affinities of CRBPI and CRBPII for 9-cisretinoids. Biochim. Biophys. Acta 1810, 514-518.

Kane, M. A., Folias, A. E., Pingitore, A., Perri, M., Obrochta, K. M., Krois, C. R., Cione, E., Ryu, J. Y., and Napoli, J. L. (2010). Identification of 9-cis-retinoic acid as a pancreasspecific autacoid that attenuates glucose-stimulated insulin secretion. Proc. Natl. Acad. Sci. U.S.A. 107, 21884-21889.

Kedishvili, N. Y., Chumakova, O. V., Chetyrkin, S. V., Belyaeva, O. V., Lapshina, E. A., Lin, D. W., Matsumura, M., and Nelson, P. S. (2002). Evidence that the human gene for prostate short-chain dehydrogenase/reductase (PSDR1) encodes a novel retinal reductase (RalR1). J. Biol. Chem. 277, 28909-28915.

King, G., and Holmes, R. (1998). Human ocular aldehyde dehydrogenase isozymes: distribution and properties as major soluble proteins in cornea and lens. J. Exp. Zool. 282, 12-17.

Kumar, S., Sandell, L. L., Trainor, P. A., Koentgen, F., and Duester, G. (2012) Alcohol and aldehyde dehydrogenases: retinoid metabolic effects in mouse knockout models. Biochim. Biophys. Acta 1821, 198-205.

Lin, M., and Napoli, J. L. (2000). cDNA cloning and expression of a human aldehyde dehydrogenase $(\mathrm{ALDH})$ active with 9-cis-retinal and identification of a rat ortholog, ALDH12. J. Biol. Chem. 275, 40106-40112.

Lobo, G. P., Amengual, J., Palczewski, G., Babino, D., and Von Lintig, J. (2012). Mammalian carotenoid-oxygenases: key players for carotenoid function and homeostasis. Biochim. Biophys. Acta 1821, 78-87.

Lovering, A. L., Ride, J. P., Bunce, C. M., Desmond, J. C., Cummings, S. M., and White, S. A. (2004). Crystal structures of prostaglandin $\mathrm{D}$ (2) 11-ketoreductase (AKR1C3) in complex with the nonsteroidal antiinflammatory drugs flufenamic acid and indomethacin. Cancer Res. 64, 1802-1810.

MacLeod, A. K., Mcmahon, M., Plummer, S. M., Higgins, L. G., Penning, T. M., Igarashi, K., and Hayes, J. D. (2009). Characterization of the cancer chemopreventive NRF2dependent gene battery in human keratinocytes: demonstration that the KEAP1-NRF2 pathway, and not the BACH1-NRF2 pathway, controls cytoprotection against electrophiles as well as redox-cycling compounds. Carcinogenesis 30, 1571-1580.

Martin, H. J., and Maser, E. (2009). Role of human aldo-keto-reductase AKR1B10 in the protection against toxic aldehydes. Chem. Biol. Interact. 178, 145-150.

Martras, S., Álvarez, R., Gallego, O. Domínguez, M., De Lera, A. R., Farrés, J., and Parés, X. (2004). Kinetics of human alcohol dehydrogenase with ring-oxidized retinoids: effect of Tween 80. Arch. Biochem. Biophys. 430, 210-217.

Mertz, J. R., Shang, E., Piantedosi, R., Wei, S., Wolgemuth, D. J., and Blaner, W. S. (1997). Identification and characterization of a stereospecific human enzyme that catalyzes 9-cis-retinol oxidation. A possible role in 9-cis-retinoic acid formation. J. Biol. Chem. 272, 11744-11749.

Napoli, J. L. (1999). Interactions of retinoid binding proteins and enzymes in retinoid metabolism. Biochim. Biophys. Acta 1440, 139-162.

Novotna, R., Wsol, V., Xiong, G., and Maser, E. (2008). Inactivation of the anticancer drugs doxorubicin and oracin by aldo-keto reductase (AKR) 1C3. Toxicol. Lett. 181, 1-6.

Parés, X., Farrés, J., Kedishvili, N. and Duester, G. (2008). Mediumand short-chain dehydrogenase/reductase gene and protein families: medium-chain and shortchain dehydrogenases/reductases in retinoid metabolism. Cell. Mol. Life Sci. 65, 3936-3949.

Penning, T. M. (2005). AKR1B10: a new diagnostic marker of non-small cell lung carcinoma in smokers. Clin. Cancer Res. 11, 1687-1690.

Penning, T. M., Burczynski, M. E. Jez, J. M., Hung, C. F., Lin, H. K., Ma, H., Moore, M., Palackal, N., and Ratnam, K. (2000). Human 3alpha-hydroxysteroid dehydrogenase isoforms (AKR1C1-AKR1C4) of the aldo-keto reductase superfamily: functional plasticity and tissue distribution reveals roles in the inactivation and formation of male and female sex hormones. Biochem. J. 351, 67-77.

Penning, T. M., and Byrns, M. C. (2009). Steroid hormone transforming aldoketo reductases and cancer. Ann. N. Y. Acad. Sci. 1155, 33-42.

Penning, T. M., and Drury, J. E. (2007) Human aldo-keto reductases: function, gene regulation, and single nucleotide polymorphisms. Arch Biochem. Biophys. 464, 241-250.
Penning, T. M., Jin, Y., Steckelbroeck, S., Lanisnik Rizner, T., and Lewis M. (2004). Structure-function of human 3 alpha-hydroxysteroid dehydrogenases: genes and proteins. Mol. Cell. Endocrinol. 215, 63-72.

Penning, T. M., and Lerman, C. (2008). Genomics of smoking exposure and cessation: lessons for cancer prevention and treatment. Cancer Prev. Res. (Phila.) 1, 80-83.

Pogenberg, V., Guichou, J. F., VivatHannah, V., Kammerer, S., Perez, E., Germain, P., De Lera, A. R., Gronemeyer, H., Royer, C. A., and Bourguet, W. (2005) Characterization of the interaction between retinoic acid receptor/retinoid X receptor (RAR/RXR) heterodimers and transcriptional coactivators through structural and fluorescence anisotropy studies. J. Biol. Chem. 280, 1625-1633.

Quick, T. C., and Ong, D. E. (1990). Vitamin A metabolism in the human intestinal Caco-2 cell line. Biochemistry 29, 11116-11123.

Quinn, A. M., Harvey, R. G., and Penning, T. M. (2008). Oxidation of $\mathrm{PAH}$ trans-dihydrodiols by human aldo-keto reductase AKR1B10. Chem. Res. Toxicol. 21, 2207-2215.

Ruiz, F. X., Gallego, O., Ardèvol, A., Moro, A., Domínguez, M., Álvarez, S., Álvarez, R., De Lera, A. R., Rovira, C., Fita, I., Parés, X., and Farrés, J. (2009). Aldoketo reductases from the AKR1B subfamily: retinoid specificity and control of cellular retinoic acid levels. Chem. Biol. Interact. 178 , 171-177.

Ruiz, F. X., Moro, A., Gallego, O., Ardèvol, A., Rovira, C., Petrash, J. M., Parés, X., and Farrés, J. (2011a). Human and rodent aldo-keto reductases from the AKR1B subfamily and their specificity with retinaldehyde. Chem. Biol. Interact. 191, 199-205.

Ruiz, F. X., Porté, S., Gallego, O., Moro, A., Ardèvol, A., Del Río, A., Rovira, C., Farrés, J., and Parés, X. (2011b). Retinaldehyde is a substrate for human aldo-keto reductases of the 1C subfamily. Biochem. J. 440, 335-344.

Shen, Y., Zhong, L., Johnson, S., and Cao, D. (2011). Human aldo-keto reductases 1B1 and 1B10: a comparative study on their enzyme activity toward electrophilic carbonyl compounds. Chem. Biol. Interact. 191, 192-198.

Shirakami, Y., Lee, S. A., Clugston, R. D., and Blaner, W. S. (2012). Hepatic metabolism of retinoids and disease 
associations. Biochim. Biophys. Acta 1821, 124-136.

Tammali, R., Ramana, K. V., Singhal, S. S., Awasthi, S., and Srivastava, S. K. (2006). Aldose reductase regulates growth factor-induced cyclooxygenase- 2 expression and prostaglandin E2 production in human colon cancer cells. Cancer Res. 66, 9705-9713.

Tang, X. H., and Gudas, L. J. (2011). Retinoids, retinoic acid receptors, and cancer. Annu. Rev. Pathol. 6, 345-364.

Theodosiou, M., Laudet, V., and Schubert, M. (2010). From carrot to clinic: an overview of the retinoic acid signaling pathway. Cell. Mol. Life Sci. 67, 1423-1445.

Verma, M., Martin, H. J., Haq, W., O'Connor, T. R., Maser, E., and Balendiran, G. K. (2008). Inhibiting wild-type and C299S mutant AKR1B10; a homologue of aldose reductase upregulated in cancers. Eur. J. Pharmacol. 584, 213-221.

Wang, C., Yan, R., Luo, D., Watabe, K., Liao, D. F., and Cao, D. (2009). Aldo-keto reductase family 1 member B10 promotes cell survival by regulating lipid synthesis and eliminating carbonyls. J. Biol. Chem. 284, 26742-26748.

Wang, R., Wang, G., Ricard, M. J., Ferris, B., Strulovici-Barel, Y., Salit, J., Hackett, N. R., Gudas, L. J., and Crystal, R. G. (2010). Smokinginduced upregulation of AKR1B10 expression in the airway epithelium of healthy individuals. Chest 138, 1402-1410.

Xi, J., and Yang, Z. (2008). Expression of RALDHs (ALDH1As) and CYP26s in human tissues and during the neural differentiation of P19 embryonal carcinoma stem cell. Gene Expr. Patterns 8, 438-442.
Yoshida, A., Hsu, L. C., and Dave, V. (1992). Retinal oxidation activity and biological role of human cytosolic aldehyde dehydrogenase. Enzyme 46, 239-244.

Zeindl-Eberhart, E., Haraida, S., Liebmann, S., Jungblut, P. R., Lamer, S., Mayer, D., Jager, G., Chung, S., and Rabes, H. M. (2004). Detection and identification of tumor-associated protein variants in human hepatocellular carcinomas. Hepatology 39, 540-549.

Zhong, L., Shen, H., Huang, C., Jing, H., and Cao, D. (2011). AKR1B10 induces cell resistance to daunorubicin and idarubicin by reducing C13 ketonic group. Toxicol. Appl. Pharmacol. 255, 40-47.

Conflict of Interest Statement: The authors declare that the research was conducted in the absence of any commercial or financial relationships that could be construed as a potential conflict of interest.

Received: 23 December 2011; paper pending published: 31 January 2012; accepted: 19 March 2012; published online: 17 April 2012.

Citation: Ruiz FX, Porté S, Parés $X$ and Farrés J (2012) Biological role of aldoketo reductases in retinoic acid biosynthesis and signaling. Front. Pharmacol. 3:58. doi: 10.3389/fphar.2012.00058

This article was submitted to Frontiers in Experimental Pharmacology and Drug Discovery, a specialty of Frontiers in Pharmacology.

Copyright (C) 2012 Ruiz, Porté, Parés and Farrés. This is an open-access article distributed under the terms of the Creative Commons Attribution Non Commercial License, which permits noncommercial use, distribution, and reproduction in other forums, provided the original authors and source are credited. 